\title{
"Femicide" Perils of a Nigerian Policewoman's Family Life
}

\author{
Kemi Olowu* \\ Principal Librarian, NIALS, Lagos, Nigeria \\ *Corresponding Author: Kemi Olowu, Principal Librarian, NIALS, Lagos, Nigeria

\begin{abstract}
Traditionally a woman is seen as a plague in the workplace, neither the maternity leave, bulging tummy or school running is acceptable to employers. Several culture of the world do not cheer at a gender birth. When it becomes a sine qua non for women to be employed, stringent rules that deter her from career advancement are given, sometimes midway through the game. Occupational stressors in the stereotyped professions coupled with administrative policies and public and cultural perception make women police develop low psychological well being. Women in male dominated professions (WMDP) generally struggle with structures that make it imperative to forfeit stereotype of gentleness, meekness and the nature bequeathed role of pregnancy and raising of children. Obedience to lawful instructions from superiors, irregular work schedules, triangular lifestyles, professional demands, family/ domestic duties are stress inducing agents. The exploratory study labors to canvass women emancipation in the 12 uniform forces in Nigeria. Women are to attend to female suspects/victims, so there will be no abuse of power or derailment of the course of investigation and accompany juvenile offender. They are however to cope with draconian laws in the Police Act governing marriage of women. Several could not meet the provisions till the biological time ticked them off! Moderate attempt is made in this study to advocate that these laws be completely knocked off by an amendment as the liberation of women is overdue. To make the work empirical, an oral research undertaken took the researcher to 5 police formations were visited in Lagos, S. West Nigeria, to interact with police women on their marital/family life.90 subjects were sighted however 45 agreed to interact and cheerfully responded. The Oath of Secrecy forbids disclosure of trade secrets in all the forces, WOPOL in particular are afraid of job loss. Exploratory studies were used and the data was analysed to show 1 out of 5 WOPOL of marriageable age are married.
\end{abstract}

Keywords: WOPOL, Women in Male Dominated Professions (WMDP), draconian laws, gender initiative, statutory change.

Epilogue: "Plague in the workplace”.... Church's position or early Christian doctrine is that a woman was represented at the door of hell as mother of all ills. She is to live in continual penance on account of curses brought upon the world. ... for this is the memorial of her fall. She should be especially ashamed of her beauty, for it is the potent instrument of Satan*

\section{INTRODUCTION}

The world is polarized along inequality of sex, race, age, class and other social distinctions. Journey into gender bias starts with the attitude towards son preference, women in Asia and Africa are specially more comfortable with male births because of inheritance rights. To be female is to be totally disadvantaged, relatively powerless, and of low status Amin et al (1994) concluded that Bangladesh people prefer two sons to the other sex to guard against loosing an only one to death or the problem of widowhood when a daughter loses her spouse. Faisalabad (1990) says Pakistanis, for cultural reasons, prefer sons to daughters. Among Yorubas non-existence of a male offspring are rampart reasons for polygamy. Eritreans like the Yorubas of Nigeria have a say 'that better a dead child than a dry womb and half bread is better than none' when it is a female birth. Shah (2010) in his article on son preference, opines that in Pakistan, arrival of a female child is seen as a waste to the agriculturist. Saha and Saha (1998) opined that for fear of the extinction of the family name, married women are not duly regarded until they have a male child.

The matter is compounded by illiteracy and economic conditions. These are the days of the old brides and late marriages are the norm for economic reasons. As only wealthy men can marry with ease, even the fact that a woman is wealthy may not guarantee a suitor. Sons according to Blankoff (1990) are economic assets, pose minimal financial and psychological stress, provide security in old age and 
are more acceptable in labor market. Childhood mortality has been linked to sex at birth in Bangladesh, Chen (1980) found out that parental care, feeding and treatment of illness were showered on the son than on the daughter, when they are between the ages of 01-04 years. Ditto in South Africa and among the Yorubas. International Labour Organisation (ILO) Gender and Equality Branch after revisiting the plight of women, says there is much to be done on gender equality in the workplace in preparation for centenary celebration of ILO. Disenfranchised part of this in S. Arabia, were granted state permission to vote for the first time in the 2015 elections. (See front page of The Guardian of 14/12/2015) Indeed the diminishing status of women is represented in all forms of inequalities that permeate the Islamic states. They are male dominated in social life and sex discrimination is perceptible in the workforce. Their morbid aversion for female involvement in public life is only comparable with ancient Rome's reprehensible perception of women as a mule who must be under the control of her hubby or eldest son.

Further proof is reflected in UNESCO Statistical Yearbook 1988 which reported that 54\% of Africans are illiterate, of this percentage, $60 \%$ are women who were not educated due to cultural beliefs. In a study by Akinnawo and Fakayinu (2010) on Women in Male Dominated Professions (WMDP), concurred that women are underrepresented in key positions. Teaching, nursing, hospitality, farming professions sex work which are all dominated by women, even discriminate against women in top posts. This is psychological than physiological. Investigative and administrative qualities do not diminish with sex. On the dishonesty ladder, women are more careful in getting involved with corruption than men too. Biological distinctions certainly mark the gender species and prescribe social destiny. Despite global efforts via Instruments like Bullying and harassment at work HMSO ACAS 2010 and United Nations moves at improving the lives of women in Mexico 1975- World Conference on Women (first ever) two other Conferences during UN Decade for women (1976-1985), topped by World Conference in Beijing 1995 , in which Nigeria featured, not much success has been recorded. Set agenda for advancing women rights and gender equality seems unattainable. In other professions, the 1979 UN Convention on Elimination of all Forms of Discrimination against Women ratified by 189 states has shifted rights of all women positively though.

\subsection{History of Policewomen Enrolment}

The police is where chivalry gives way to chauvinism. With the enlistment of Perry Harrington, the first WOPOL in USA, the initial role conceived for policewomen is a reflection of traditional gender roles- handling women and children, especially sex offenders, clerical duties and as orderlies, etc.Ss.121-122 of Cap19 of LFN2004 list these. This under-researched and underserved groups of women, who are particularly vulnerable to violent victimization from close associates and greatest resistance to advancement from male colleagues, are reluctant to disclose their plight even with the instrument of a questionnaire. There is an understandable secrecy in addressing this so as to be in tandem with the privacy norms of the force. Oath of Secrecy LFN 2004 Cap 01, S.2 is administered to all in uniform upon enrolment. Sequel to this is the listing of offences against force discipline in the First Schedule of the Police Act and Regulation 370B (i, iii-iv) Breach of Confidence for Force members: Any member is guilty if he

i) Divulges any matter which is his duty to keep secret

ii) Without prior authority, communicates to the public press, or to an unauthorized person, any matter connected to the Force....

iii) Without prior authority, shows to a person outside the Force any book or document the property of the government or the Force.

The question that readily comes to mind is, is this article not one of such breach of confidence? Everything lawful is permitted under academic freedom, within the ambits of teaching, learning and research.

Akinawo and Fakayinu (2010) observe the need for swift balance in gender composition in the police, though the women are faced with great stressors which adversely affect their health and overall well being. He concurs that women in male dominated professions such as hunting, policing, military, politics, seamanship, haulage trade, mining, excavations, ethnic militancy, rag tag army, truck loading are often single, barren or have fewer children, generally live alone though married and are likely to engage in illicit amorous relationships. 
The vulnerable group in this study constitutes the minority in the police formations like the other male minorities in the air wing, artisans, music (police band), railway police, medics, education sector, veterinary police (force animals :dogs and horses), supernumerary, volunteers etc. Since their recruitment is an afterthought, impossible laws are drafted that make them 'fall out' fast . Jobs that are brutal, repulsive, obscene or hostile have often barred women from their shores, hence, WOPOL after economic reality of WW1 perform police duties but only engage in night duties during great distresses, they are to remain in the station as backup or reserves in case women or children are brought in as suspects.

Premium on physical strength is the reason for their exclusion from core policing duties such as exchange of duel or fire with bandits. Prerequisite for policing is to be overly masculine- hazardous situations of urban guerrillas, bombing, hostage taking, snipers, assassinations, unwarranted but premeditated assaults, enforcement of court injunctions, mass rally, etc necessitate use of brutal force, built only into men. Feminist sociological gender research on women studies/vulnerable populations, discovered these professions defeat publicly, age long role of homemaking and childbearing/raising for women. Post 1945 war developments however, have seen women pick these up due to conscriptions, adventurous, economic or uninformed reasons. The gentle nature of women presumes naturally they shall interact with female and child offenders, investigate female victims of sex related crime (rape/defilement), serve as orderlies to female VIPs/ heads of states (Aide de Camp), perform office orderly duties, clerical duties (typist) and attend to women processions (violent or otherwise).

\section{PEREMPTORY DUTIES OF WOPOL}

The policeman's role to the female victims or offenders was unsatisfactory and controversial. Policemen per se or as lieutenants or support service givers had no woman at inception. Documentary on police role in rape cases was featured by BBC on 18 January 1982 to protest against this hatred for WOPOL. In another, a male police force was posted to quell a riot of more than half of them women. These are to muffle the populace who hated feminine enlistment. In 1814, Metropolitan police department enlisted the first WOPOL to investigate woman and family related issues. METPOL women branch was initially formed in 1917 to formalize women's role in WW1. They featured in voluntary capacity as well as part time police on emolument. Since 1907, all police formations have women in dual capacity serving as civilian mediators or available reserves. As during investigation, she takes statements,(illiterate suspects),scoop forensic evidence from minors and gender based violence victims. She was employed as auxiliary, available reserve, as her chemistry aids police investigation.

Even as rockers of street corners, band of young football supporters, urban industrial helps, etc. Attitude and behavior to these weaker vessels has been discriminatory and glass ceiling easily frustrate serving officers to take a bow. Prejudice, differentiation and discrimination have ruled the game. Certain social groups such as children, aged, disabled, traumatized certainly need the civil, patient nature of women to attend to them in whatever state. Sequel to this is the correctional role of the police as managers of juvenile welfare centers, Borstal institutions, solation homes, Shock treatment centers, Pre-release law units, rehabilitation and other correctional or punitive homes, which need a mother figure around. Basic duties of WOPOL is supervision of female prisoners or suspects, essentially in sex offences and female offenders. For females in purdah in the Magrebs, who run a brothel, killed spouse, kid or neighbor, only policewomen (WOPOL) are desirable.

Sexual divisions in investigative duties features in stop and search, arrests, charges, convictions, incarceration (detention), confinements, etc. Opportunity to abuse these official duties and powers would be minimal when same sex interaction is the norm, at least in States where gay/ lesbian rights are not yet enhanced.

The reality of gender divisions in criminality such as whores, hard drug conveyors, abortionist, female suicide bombers, illegal distillation of alcohol make assigning a WOPOL an imperative, nowadays, indeed gender offending rates parallel male peers, hence police recruitment have to be in tandem with the development. In India, each area command must have $12 \mathrm{WOPOL}$, this seems to be the standard in Nigeria NPF.

Attempts have been made to assess the effect of gender as victims or as suspects on policewomen in the crime branch and the result shows normalcy. Thus assigning of WOPOL to female victims of crime or suspects is the global practice. 
Indeed the force literature on this are restricted to very senior police officers (SPOs) government officials and few researchers due to the low literacy and psychological levels of these other ranks.

\subsection{Conditions Governing the Marriage of a WOPOL}

After the initial 1956 debut in Nigeria of gender in the police, these same rules still govern the conditions of service. At best WOPOL can be introduced as appendages, this moderate attempt is to break the chain of "slavery", perhaps this can be an impetus for further studies. It is to also create awareness on this regimental albatross.

Their recruitment is seen as a burden and the culture and socialization of the force detest WOPOL. The hiring drills, workplace harassment are repulsive, fraternization or workplace dating are legally prohibited, though this still occurs. This is a cursory look about unification of standards among international organizations to vet issues affecting female law enforcers. An international candidate assistance program in Australia had to wade in at inception that, globally, WOPOL because of the feminine compassion, warmth, conviviality, accommodating nature and no non-sense approach, must of necessity, count in all recruitments. They must never be dismissed for whatever offence against discipline. Every marriage encounters challenges. To put a high tag from the onset, as is being done in the force is tasking. How they are to devise coping strategies for straight laced life of a disciplined force, crowd/traffic control, police tactics, stunts at shooting range, role sharing to subordinates, prisoners' welfare, standing throughout the day, early morning parades/briefings, prompt signal dispatch, social discrimination by even relations, sexual abuse by colleagues and other male aggressors were not well marshaled as these stressors make occupational psychologists, count them as risk factors to family life.

\subsection{Crux of the Matter}

Challenges keeping WOPOL frustrated, exhausted and subdued by workplace stress include conditions for marriage, love advances from superiors or suspects and glass ceiling in promotion. Women hardly head sensitive units even in the Scotland yard (UK), except for intelligence bureaus. Literature on the mutual hostility towards WOPOL can be found in official documents cited in Sections 121-128 of the Police Act Cap19 LFN 2004 which highlight the duties

\section{Section 121: Duties of a police woman}

1) Investigation of sexual offences against women and children

2) Recording of statement from female witnesses and female accused and children

3) Attendance when women and children are being interviewed by superior officers (SPO)

4) Searching, escorting and guarding of women prisoners in the stations, and while on the move

5) School crossing duties

6) Crowd control when women and children are involved e.g Protests, IDP camps, electioneering campaigns

7) Clerical duties, telephones and orderly duties to visiting female HOS/VIPS

8) Running of juvenile welfare centers.

S.124: Women police to apply for permission to marry

A woman police who is desirous of marrying must first apply in writing to COMPOL for the area command in which she is serving, requesting permission to marry and give the name, address, occupation of person she intends to marry. Permission will be granted for the marriage, if the intended husband is of good character"

\section{S.125 No special privileges to be granted to married women police}

A married woman police shall not be granted any special privileges by reason of the fact that she is married, and shall be subject to posting and transfer as if she were unmarried'

S. 127: An unmarried woman police who is pregnant shall be discharged from the Force and shall not be enlisted except with the approval of the IGP.'

WOPOL law states that transfer and postings to any states of the federation is also unhindered by marital status! The only similitude of writing unit head before contracting a marriage is found in the 
Public Service Rules : Foreign Service Regulation- Regulation No 6. Rules for Foreign Affairs officer request writing in so that his/her allegiance to the nativity is not compromised. Also to guarantee her allegiance as a representative abroad and limit the number of postings she may be deployed. If her utility will diminish, she shall be compelled to leave the foreign service. The force rules contrarily, say even though married she shall be transferred as if unmarried!

Other limitations of WOPOL are not rehearsed so as not to wash dirty linens in public or breach ethics of a research. Example is the care of suspect in detention which are often not budgeted for - feeding, treatment, tactful enquiry trips, Police officers wives Associations(POWA) exist and not POHA (Police Husbands Association), wives can be accommodated in barracks and not hubbies, POWA recognized by the law and not female officers' hubbies. The 2 arms of civilian spouses never enjoy equal rights in barrack allotments, officers' mess attendance, bereavement allowances, etc. Women are less aggressive and hate competitiveness in the workplace. Police literature generally come from policemen/women, the tendency to give a subjective and not objective view is overriding. Regrettably too much is concentrated on police dismal performance of duties and not ephemeral topics as this.

These discriminatory laws on marital rights of WOPOL are still featuring and correction is certainly a doable task. Portugal and Netherlands have made positive moves towards this in their Police Acts.

\subsection{Israel's Role for Female Officers}

Due to the nature of Israeli's possession of Palestine since 1948 and incessant Arab/Israeli conflict, which international researchers concluded defies a lasting solution, there is no non military service for the Jews. The national setting is a utilization of military -supported activities in transportation, hospitalization, communication, construction, education, etc. Immediately Israel became a State in 1948, The Defense Service Law of 1949 came to compel all youths; irrespective of gender to be enlisted at age 18. Hopes of demilitarizing Israelis deems by the day, hence agriculture, settlements, immigrant groups, tourism, civil service and other civil and otherwise light activities are militarized because of their hostile neighbors. Socialization is entrenchment of military into their very fabrics. To this end, not even the disabled or socially disadvantaged (school drop outs) are exempted. The Israelite is ready for combat as a male or female member of Israeli Defense Force(IDF). 'Chen' (Hebrew word for charm), Israeli version of WOPOL is the label for women soldiers, who are often employed to carry non-military but strategic functions like nurse's aide, rehabilitation of street girls, teaching in war torn zones and other social welfare services. This explains why Israel is a no-non sense society. Other names for the military women are Yachas, Hibas, Auxillary Police or Sherut Leumi. The names depict female military personnel. This is a noble example as police and military duties are merged-external aggression from Palestinians are more rampant than civil upheavals. The incessant police and military bloody clashes as we have in Nigeria is thus non existent.

\subsection{Sunny Side of WOPOL Lifestyle}

It is not all about inability to maintain a private life as a WOPOL, the dilemma of which shoes, clothes, accessories to put on to work daily is eliminated as the uniform is a signatory tune. Women agree this can be a daunting task a times. S.128 expresses this fact, while on duty

A woman police officer in uniform shall not

a) Wear face powder or lipstick, or ...nail vanish...

b) Wear any article of jewellery other than a wedding ring ... or wristwatch

c) Dress her hair in such fashion that it falls over the uniform collar... the plaits are to be tucked under the uniform cap

Be that as it may, she spends less on clothing as the prescribed ones are provided by the State. The bulk of civilian ladies' budget goes on such ephemerals which she actually has no need of. Feminism endeavors have revealed other sunny side of WOPOL marital life, they never undergo domestic violence, the spouses knowing well they are trained exhaustively in drills, she is trained to be an aggressor by virtue of the training in unarmed combat (fighting to kill with bear arms). The spouses are to report her misdemeanors to the unit head.

Male hostility (assault) to female counterparts are less pronounced at workplace as the force members enjoy camaraderie in general, though not in terms of promotion, WOPOL do not come for night duties 
and bandits hardly ever assault them, postings to warfront is forbidden, as the male officers will be at the dilemma of protecting them than face the actual enemy combatants. They are allotted barracks spaces with ease, faster than male colleagues. horrors from terrifying landlords are hardly experienced, but compliance with stringent barrack rules is a must. E.g. no trading, parties, fighting, rearing of animals, bickerings, and the like. The Regimental Sergeant Major (RSM) may impose rules as the exigencies call for. No law or traffic officers can stop and search their vessels, vehicles or persons.

\section{RECOMMENDATIONS}

1) Quest for family life: Gender psychopathologists have concluded that no woman is complete without family life, irrespective of whether children are social security in old age or not. Despite the vicissitude of marital life, every person desires to marry. Socio-cultural beliefs detest a lone ranger in Africa except one is in a profession where celibacy is the norm (seminarian or other devotees). WOPOL should not be clandestinely confined to singleness by undue scrutiny. A woman by nature, will rather babysit for instance than go for a refresher course or promotion exam. This explains why so many leave the service prematurely. A WOPOL for instance would rather go and babysit than continue her education or attend promotion or career development trainings. Family ties should not be severed to answer to duty. Premature and hasty decamping to civilian life would be common, as either she is relocating with the husband, unable to attend refresher courses outside her location, or reluctant to bring suitor for scrutiny. The funds spent in training her is thus wasted. As these laws are certainly an indices to early departure from the strict Force discipline.

2) Career breaks: Gender discrimination thrives on culture of silence, that must be broken. The forces are not known to address press conferences as this is tantamount to mutiny. Women in whatever profession should not be made to sacrifice family life and procreation for any duty. Career breaks, sabbatical leaves as in the academia, half pay while on maternity leave, no woman should be transferred out of duty post, working hours strict adherence(no overtime), are ideas that can be tinkered with.

3) Legislation on WOPOL: Draconian marital laws should be expunged altogether, as to submit husband-to-be for interrogation is obtrusive, emotionally depressing, nightmarish and amount to a privacy invasion. Goal 3 of UN SDGs by 2015 aims at promoting Gender Equality and Empowerment of women.

4) Frequent career drop outs will continue to be rampant after rigorous training at the Police colleges and academies as women who detest these marital laws will decamp to civilian life. Extremely dangerous trend as forces in all climes are trained with instruments of cruelty. Ab initio, state these draconian laws on the website or all literature made available for public consumption prior to recruitment.

5) Equal opportunity for advancement: These should be accorded all WOPOL. So much is already lost for donning the uniform than the male counterparts. Under the aegis of UN, 1975 was the year of the Women, as usual African representatives lacked scientific and information database and other documents to exhibit at their continent's delegation stand at the Mexico Conference. Detailed documentation of infecting partners with STD, domestic violence, violation of the creed of Marriage Act by married couples (polygamy), were never reported by African women. Nothing has changed too since 1994 Beijing Convention (CEDAW). A rehersal of another Convention in 1979 did not take any cognizance of women under this discourse. Status of women in all professions neither shifted. These instruments should move beyond paper tiger and quell all gender inequality.

6) Policy on bullying or sexual harassment in the workplace: The judicial system is equally unhelpful in this regard. A woman is stigmatized for reporting advances from her boss in fact, it is trivialized, as man's aggression is tacitly backed by law. It is acceptable and not worth reporting and to do otherwise is to be laughed to scorn. Little wonder most women are sex slaves to the male aggressors in the work environments. Many WOPOL suffer in silence as a few bosses deliberately deny approval for marriage and convert these women to personal property through office romance, laws forbidding any amorous relation exists only on paper and if possible a law as grave as death sentence for officers who date WOPOL should be devised. This is to be a voice to the voiceless WOPOL suffering in silence. 


\section{CONClusion}

S. 123 of the Police Act states:

Women police not to drill under arms

A woman police officer shall not be called to drill under arms

(and ammunitions) or to take part in any baton or riot exercise

With increased hostility and unpredictability of where and when a WOPOL will find herself. Either as back up or reserves during emergencies, this section has been muffled and all WOPOL partake in small and medium arms drill, to the level of firing armored tanks, propelling rocket launchers etc. Indeed when late Mohamar Gaddafi of Libya visited Nigeria in the 1980s all his VIP squad were Libyan female army officers and they functioned effectively, and that in an Islamic state! If this section of not drilling in arms lacks power, then all gender discriminatory laws should follow suit and be cleverly expunged. To do otherwise is to support tacitly the notion that she and indeed all women are a plague in the workplace. As this work was being concluded, SaharaReporter sent a report online, that Nigerian Court nullifies police 'Marriage permit'- Female cops can now marry without permit from the NPF. The gist is that a Federal High Court in Lagos declared illegal the said provision in the Police Act which compels a policewoman to seek her command's C.O.P. written approval before contracting a marriage. An N.G.O., Women Empowerment and Legal Aid Innitiative (WELA) questioned the relevance of Regulation 124 of LFN Cap P19 Police Act. The provision is sequel to the preceeding ban from marriage for the first three years after enlistment. These gender activists related the provision to primordial times when female slaves (maids) were killed once she takes in (Efunsetan Aniwura tale of South West, Nigeria). This is contrary to S.42 of 1999 Constitution and Article 2 of African Charter on Human and Peoples Rights, to relay her thoughts. The two statutes prohibit discrimination on accounts of sex. Nigeria signed several Treaties like, Convention on the Elimination of All forms of Discrimination Against Women (CEDAW), African Charter on Human and Peoples Rights (Protocol on the Rights of Women in Africa). The group coordinator rules that the sections must be expunged from the Police Act. While it is ideal to advocate for a free work environment for cops, the danger of fraternisng with would be suspects in the barracks is the dread. It is very commendable that since the inception of this gender biased laws by the NPF, no suitor has ever been contacted and given negative posts on any policewoman.

\section{APPENDIX}

Visits were undertaken to 5 Police formations viz:

1)Motor Traffic Division(MTD) Sagamu Rd, Ikorodu- 10subjects: 8 married

2) Area H, Command HQ, Surulere- 10subjects: 2married

3) Bariga Police station, Ilaje-10subjects: 4 married

4) WOPOL Barracks Obalende. 50subjects:25 married

5) Ketu Police Station, Ketu- 10subjects: 6married

Less than half agreed to interact with this researcher during the informal interview sessions, due for the Oath of Secrecy Act, may be with little funds to buy gifts to induce them, they may be more responsive to interviews.

The complete records of policemen/women in Nigeria can be retrieved from MSD (management services department). The Force headquarters (FHQ) where the department is domain is in Abuja. It would have been ideal to know the ratio of police women to the men at any point in time to vet the compliance with the directives on ratio of WOPOL to male officers.

\section{REFERENCES}

[1] Akinawo,E.O. \& Fakayinu, R. Determinants of job \& life dissatisfaction of NPF officers Gender and Behavior Vol. 8(2) 2010.3314-3327

[2] Asobele,T. (2002) The prostitute or the plague, $1^{\text {st }}$ ed. Gos, Rothmed International Ltd. 5-7

[3] Badawi, J.A. (1984) Status of women in Islam\& truth about polygamy. London, OUP 1-9,26.

[4] Brogden, Jefferson (1984) Introduction to Police work London, Walklate.115-118 
[5] Chouwen, C.O. Experience along the glass ceiling: Tactics of female executives Ife Psychologia Vol.11 (1) 2003.804

[6] Collins, O. ILO hinges future of work on women. The Guardian Lagos (27 October 2015) 45

[7] Gabasa P. (2015) Prison libraries: case of Kirikiri Prison. Paper presented at NIALS staff seminar series. 4-5

[8] Gold, M. (2000) Top Cops: Profile of women in command $2^{\text {nd }}$ ed. London, Cost \& Coy. 8-9

[9] Leonard, V.A.(1980) Fundamentals of law enforcement: Problems \& prospects Minnesota, St Paul.71.

[10] Lunneborg, P. Womenpolice: Portraits of success $1^{\text {st }}$ ed. Texas, Brogden.115

[11] Okafor, A.D. \& Essien, S. E. (eds) 2nd NYSC Global Conference, 10-14 Oct. 1994. Gabumo Publishers Ltd. Lagos.103-105

[12] Owing, C.(1969) Womenpolice :Study of development \& status of policewomen movement. London, Patterson Smith. 234

[13] Oyesoji, S. Beyond police barracks: research synthesis of counselling psychologist. Ife Psychologia Vol. 13(1) 2005.94

[14] Omideyi, A.K. Demography \&social statistics, female autonomy, socio-economic status and inductive behaviour in Sub-Saharan Africa. Ife Psychologia Vol.5(1) 1998.1002

[15] Police Act, LFN 2004 Cap 19, Ss118-128

[16] SaharaReporter of May 12,2020

[17] Shah, Mussawar Son preference and its consequences Gender and behavior Vol. 3, June 2005345.

[18] Thomson, W., Introduction to Police. Australia, St Paul. 317

[19] United Nations Information Centre (UNIC) 70 ways the UN makes a difference.2017.37

[20] www.ngrs./gov/policing visited @ 02/11/15

Citation: Kemi Olowu. " "Femicide” Perils of a Nigerian Policewoman's Family Life" International Journal of Humanities Social Sciences and Education (IJHSSE), vol 7, no. 10, 2020, pp. 28-35. doi: https://doi.org/10.20431/2349-0381.0710003.

Copyright: () 2020 Authors. This is an open-access article distributed under the terms of the Creative Commons Attribution License, which permits unrestricted use, distribution, and reproduction in any medium, provided the original author and source are credited. 